\title{
LA GERENCIA INTERPELADA: EDUCACIÓN EN GESTIÓN VERSUS FORMACIÓN EN VALORES
}

\author{
VIVIANA H. PEÑA \\ - Profesora de Fundamentos de la Gerencia \\ Área Académica de Administración, UPC
}

El caso Lava Jato ha desatado el, probablemente, mayor escándalo empresarial que la historia haya conocido. Una trama escalofriante, cuyo esclarecimiento está aún en proceso. Apenas conocemos la punta del iceberg. Sin embargo, los primeros detalles revelan una contundente realidad: la corrupción instalada en el seno de nuestra sociedad y en sus instituciones. ¿Qué nos ello dice del carácter de la gestión?

Los personajes en escrutinio son ejecutivos de alto nivel de reconocidas empresas y funcionarios de gobierno de doce países, diez de ellos de nuestro continente, que ahora son investigados por sobornos de alrededor de 786 millones de dólares que se dieron con el objetivo de obtener los favores y beneficios derivados de la ejecución de obras de interés nacional y de gran envergadura. Otros muchos estamentos se han articulado alrededor de esos actores: se habla de bancos y empresas offshore de cuatro capas; de partidos políticos y candidatos ávidos de poder: de testaferros y otros intermediarios, muchos de estos, gerentes de varias decenas de firmas a lo largo y ancho de América Latina.

La idea de que los actores sociales siguen reglas internalizadas de lo que se define como normal, cierto, correcto o bueno, a pesar de las consecuencias o de los beneficios esperados, es de larga data, desde Sófocles hasta Martin Luther King. Los modelos utilitarios, que postulan la maximización de los beneficios ante una decisión, no se condicen con las características de las decisiones éticas. Siguiendo a March y Olsen, nuestra democracia se fundamenta en la lógica de lo apropiado. Esta es una perspectiva bajo la cual las acciones se guían por aquellas conductas ejemplares que se dan en el interior de las instituciones. Las reglas se siguen porque son vistas y valoradas como correctas, esperadas y legítimas; y los actores cumplen un rol en el ejercicio ético de su práctica, como parte de su identidad dentro del grupo y de acuerdo con las expectativas y los propósitos de este último. Es así que, insertados en una colectividad, los individuos hacen lo que es apropiado para la situación.
Una vez que las decisiones estratégicas hayan sido tomadas por los ejecutivos, el gerente medio es el principal responsable de la ejecución de la operación. Desde la perspectiva ética, los mandos medios constituyen un grupo particularmente sensible, puesto que se sitúan entre los imperativos de sus jefes y la estructura organizacional. Además, son los responsables del bienestar de su personal y de sus clientes. No es muy aventurado postular que son estos quienes probablemente reciben más presión de diferentes frentes y en varias direcciones cuando del punto de vista ético se trata. Con su experiencia y conocimientos, ¿qué tanto sabían de lo que estaba sucediendo? ¿Qué nivel de involucramiento tuvieron ellos y el personal a su cargo? Y, no menos importante: ¿qué conductas están modelando en los jóvenes profesionales que se incorporan al mercado de trabajo?

La teoría de lo apropiado reconoce que los aspectos identitarios (dependencia y locus de control), junto con los moderadores situacionales (cultura organizacional, estructura, eferentes y obediencia a la autoridad), son en suma las variables a ponderar, y en todas estas la gerencia media tiene mucho que decir. Partiendo de la identidad del individuo y acorde con el reconocimiento de la situación, la pregunta de rigor, y que habría que formular una y otra vez, es la siguiente: ¿qué debe hacer una persona como yo, o una organización como esta, en una situación así? Para que el tránsito por esta disquisición sea aprovechable, se necesita de un individuo capaz de pensarse y diferenciarse, con la posibilidad de identificarse con los valores organizacionales, pero también la de desidentificarse (desmarcarse) cuando la decisión así lo demande.

Requerimos una sociedad de hombres y mujeres libres para decidir y hacer lo que es correcto, en vez de lo que es fácil; sin miedo a enfrentar y defender con convicción; $y$ que expongan y denuncien lo ímprobo. Sostengo que el futuro de nuestra sociedad y el de las organizaciones está en las manos de quienes modelamos e infundimos los 
valores a los más jóvenes. En cada pequeño acto, por más insignificante que parezca, ahí donde se forma el carácter del profesional, del gerente que mañana deberá enfrentar dilemas por demás complejos y delante de quienes usarán otras premisas para intentar amilanar las voluntades y convicciones débiles.

Tal como es el espíritu de los negocios hoy, el combate a la corrupción debe ser un esfuerzo colectivo, transnacional y transdisciplinario. La educación en gestión también requiere de subjetivación. La formación continua y el aprendizaje solo son posibles a partir de la experiencia de contacto con otros, al evocar situaciones de gratificación o en su defecto de sanción, dentro de un entorno que facilite la transición del joven educando al estado adulto con la autonomía como correlato y la identidad como bandera.

El trabajo de educar jóvenes profesionales va más allá, sin que me quepa duda, de la trasmisión de conocimientos o de la adquisición de tecnologías y destrezas. La labor de los educadores está en modelar y encarnar los valores que deseamos que se institucionalicen en nuestra sociedad, renunciando conscientemente a aquello que atente contra su porvenir. Esto requiere de un monitoreo constante de las acciones y decisiones, que, por menores que parezcan, han de forjar el proceder y sentar las bases de nuestro mañana. ¡Es el ejemplo que va más allá de la prédica el mejor maestro! 